\title{
ANALYSIS OF THE FACTORS AFFECTING THE COMPLIANCE OF INTERNSHIP DENTIST IN THE IMPLEMENTATION OF PRECAUTION STANDARDS AT DENTIS'T HOSPITAL IIK BHAKTI WIYATA KEDIRI
}

\author{
Indra Cahyadinata ${ }^{1}$, Indasah ${ }^{2}$, Sandu Siyoto ${ }^{3}$ \\ ${ }^{1}$ Magister of Public Health Program, Stikes Surya Mitra Husada Kediri, Indonesia \\ ${ }^{2,3}$ Lecturer of Magister of Public Health Program, Stikes Surya Mitra Husada Kediri, Indonesia \\ Corresponding author: Indra Cahyadinata (indra.cahyadinata@iik.ac.id)
}

\begin{abstract}
Dental health personnel in carrying out daily care can not be separated from contact with saliva and blood which can be an intermediary in the spread of cross infection. Cross infection is common in medical treatment procedures including dental and oral care. Prevention of cross infection needs to be done to avoid transmission of disease from medical procedures to patients and dental health workers. The purpose of this study was to determine the factors that influence the compliance of the dentist Koas to the application of the Precaution Standard at RSGM IIK BW Kediri. The method in this study was observational descriptive with cross-sectional design. The number of samples is 67 Koas dentists using the Slovin formula. The tools and materials used in the research are check list sheets and stationery. The data processing in this study uses the SPSS program by using a binary logistic test. The results of this study indicate that from several factors that influence the compliance of dentist councils in applying the precaution standard at RSGM IIK BW Kediri is a knowledge factor of $p=0.010(<0.005)$, supervision is $p=0.003(<0.005)$, and the availability of infrastructure is $p=0.006(<0.005)$ with supervisory variables which are the variables that have the most individual influence compared to the other variables. Thus in drawing the conclusion that the level of knowledge, supervision and facilities and infrastructure is a factor that influences the compliance of dentists in implementing the implementation of precaution standards that have been set for prevention of cross infection.
\end{abstract}

Keywords: Compliance, cross infection, dentist coasions, precaution standards

Copyright @ 2019 Stikes Surya Mitra Husada. All right reserved.

\section{INTRODUCTION}

The hospital as one of the health service facilities is part of the health resources that are very much needed in supporting the implementation of health efforts. Various types of health workers with scientific tools each interact with each other. Medical science and technology that is growing very rapidly which must be followed by health workers in the framework of providing quality services, making the increasingly complex problems in hospitals (Association of Indonesian Laws and Regulations concerning Hospitals, 2010).

Infectious diseases that occur in Indonesia according to the 2013 Basic Health Research (RISKESDAS) include Tuberculosis and Hepatitis. The prevalence of hepatitis in 2013 was at the rate of $1.2 \%$, where the incidence of infection by hepatitis was two times higher than the incidence in 2007, besides the incidence of infection with Human Immunodeficiency Virus (HIV) every year continued to increase. The increasing prevalence of people infected with infectious diseases is a condition that should be watched out for especially those who work as dentists, because dentists are one of the professions that are prone to cross contamination, so that the maximum protection from dentists is needed to protect themselves from cross infection (Budiharto, 2015). The dentist profession is inseparable from the possibility to come into contact directly or indirectly with microorganisms in the blood and saliva of patients. The spread of infection can occur inhalation namely through the 
respiratory process or by inoculation or through the transmission of microorganisms from the serum and various other substances that have been infected. Evidence shows that the level of risk of the dentist is directly related to contact with the blood and saliva of the patient. This causes actions in the dental practice to place dentists at high risk especially for dangerous infectious diseases caused by viruses and bacteria.

Compliance in applying precautions is closely related to health behavior. Compliance behavior towards standard vigilance consists of worker / individual factors, work / task factors and environmental / organizational factors. Research shows that compliance with the application of standard precautions is still low due to lack of knowledge, trust in being infected is still minimal, and lack of motivation for self-protection, as well as limited facilities in prevention and control of infection, availability of hand washing facilities in available nursing rooms evenly, if available sometimes without soap and towels.

Based on the background above the researchers were interested in examining the Analysis of the Influential Factors Towards the Compliance of the Dentist's Coas in the Application of the Precaution Standards at the Dental and Oral Hospital IIK Bhakti Wiyata Kediri. Based on the background above, the formulation of the problem in this study is whether the factors that influence the dentist coefficient on compliance with the application of the Precaution Standard in the Dental and Oral Hospital IIK Bhakti Wiyata Kediri. This study aims to analyze the factors that influence the behavior of dental doctors in applying standard precautions in the Dental and Oral Hospital IIK Bhakti Wiyata Kediri.

\section{Special Purpose}

a. To analyze the effect of the dentist's co-knowledge factors on compliance with the application of the precaution standard in the Dental and Oral Hospital IIK Bhakti Wiyata Kediri.

b. To analyze the effect of dentist co-trust factors on compliance with the application of the precaution standard in the Dental and Oral Hospital IIK Bhakti Wiyata Kediri.

c. To analyze the effect of dentist co-motivation factors on compliance with the application of the precaution standard in the Dental and Oral Hospital IIK Bhakti Wiyata Kediri.

d. To analyze the effect of factor availability on compliance with the application of the precaution standard in the Dental and Oral Hospital IIK Bhakti Wiyata Kediri.

e. To analyze the effect of monitoring factors on compliance with the application of the precaution standard in the Dental and Oral Hospital IIK Bhakti Wiyata Kediri.

f. Analyzing the factors that influence the compliance of the application of the precaution standard in the Dental and Oral Hospital IIK Bhakti Wiyata Kediri. The benefits of Research is :

g. $\quad$ Contributing to the development of RSGM in Indonesia, specifically RSGM Education IIK Bhakti Wiyata Kediri.

h. As input for the Education RSGM IIK Bhakti Wiyata Kediri to reduce the possibility of cross infection between health workers and patients and vice versa in applying the Precautions standard for each health worker in the hospital.

i. As a reference material for dentists and clerical students of FKG IIK especially in implementing standard precaution procedures in hospitals so that they can prevent the transmission of disease from patients.

j. $\quad$ Providing experience and training the ability of researchers to carry out applying standard precaution procedures in hospitals.

\section{METHODS}

\section{A. Research Design}

The research design used in this study is the Transversal Study (Cross Sectional) because this study is to study the dynamics of the correlation between risk factors and effects by means of an observation or data collection approach at a time (point time aproach) means that each research subject is only observed just once and measurements are made on the character status or subject variable at the time of examination. This does not mean that all research subjects were observed at the 
same time. The purpose of this study was to observe the relationship between factors of knowledge, motivation, trust, availability of infrastructure, and supervision / supervision of compliance with the application of the Precaution Standard.

\section{Materials and tools}

a. Population

According to Arikunto (2012) population is the whole subject of research. Population is all research subjects (for example patients) who meet the established criteria (Nursalam, 2013). The target population in this thesis proposal is the co-dentist who practices at RSGM IIK BW Kediri, as many as 80 people.

\section{b. Samples}

The sample is partially taken from the entire object under study and is considered to represent the entire population (Notoatmodjo, 2012). In this study the sample in the research location is less than 100 , so the determination of the sample size can use the Slovin formula, namely:

\section{Information :}

n: Number of samples

$\mathrm{N}$ : Total population

e: The rate of sampling errors $(1 \%, 5 \%, 10 \%)$

Then from the formula obtained the sample:

$$
\begin{aligned}
& \mathrm{n}=\mathrm{N} \\
& 1+\mathrm{Ne} 2 \\
& =80 \\
& 1+68(0.05) 2 \\
& =80 \\
& 1+0.2 \\
& =80=66.67 \\
& \text { (rounded to } 67 \text { ) }
\end{aligned}
$$

\section{Equipment}

1. Practical Suit

2. Masks

3. Handscoon

4. Writing equipment

5. Camera to take pictures as supporting data 


\section{B. Variables \\ 1. Independent variable}

The independent variable is the causal variable or the independent variable. The independent variables in this study are Knowledge, Trust, Motivation, Availability of Infrastructure, Supervision / Supervision.

\section{Dependent variable}

The dependent variable is the dependent variable or the result variable. The dependent variable in this study is Compliance with the Application of the Precaution Standard

\section{RESULTS}

\section{A. Variable Analysis \\ 1. Analysis of information fitting model}

At this stage of analysis, binary logistic regression analysis is used because the dependent variable is compliance with the application of the nominal scale Precaution Standard, which is obedient and non-compliant. The results of the binary logistic regression analysis for simultaneous testing are as follows.

Table IV.13 Omnibus test for simultaneous testing of binary logistic regression

\begin{tabular}{llccc}
\hline \multirow{3}{*}{ Step 1 } & Chi-square & $\mathrm{df}$ & Sig. \\
\cline { 2 - 5 } & Step & 52,139 & 5 &, 000 \\
\cline { 2 - 5 } & Block & 52,139 & 5 &, 000 \\
\cline { 2 - 5 } & Model & 52,139 & 5 &, 000 \\
\hline
\end{tabular}

The results of the above analysis produce a sig value of 0,000 . This value is smaller than the level of research error used which is equal to $5 \%(0.05)$ so that the conclusions obtained from the results of the above analysis are there are significant influences simultaneously or together knowledge, trust, supervision, motivation, sarpras availability against compliance in applying the Precaution Standard.

\section{Analysis of Nagelkerke R Square}

Analysis of Nagelkerke R Square Analysis serves to measure the diversity of data described by binary logistic regression. Nagelkerke R Square values are presented in the table below.

Table IV.14 Nagelkerke R Square Value

\begin{tabular}{cccc}
\hline \multicolumn{4}{c}{ Model Summary } \\
\hline Step & -2 Log likelihood & Cox \& Snell R Square & Nagelkerke R Square \\
\hline 1 & $32,684^{\mathrm{a}}$ &, 541 &, 753 \\
\hline
\end{tabular}

The value of Cox \& Snell R Square logistic regression is 0.753 . This value means that $75.3 \%$ of all the diversity of data available, can be represented by a logistic regression model or an independent variable capable of explaining $75.3 \%$ of the dependent variable. 
3. Estimaste Parameter Analysis

Table IV.15 Analysis of parameters estimating binary logistic regression

\begin{tabular}{|c|c|c|c|c|c|c|c|}
\hline \multicolumn{8}{|c|}{ Variables in the Equation } \\
\hline & & B & S.E. & Wald & df & Sig. & $\operatorname{Exp}(B)$ \\
\hline \multirow[t]{6}{*}{ Step $1^{\mathrm{a}}$} & Pengeta-huan & 2,042 & ,790 & 6,681 & 1 & 010 & 7,706 \\
\hline & Kepercayaan & ,337 & ,945 & ,127 & 1 & ,721 & 1,401 \\
\hline & Motivasi & 1,021 & 805 & 1,608 & 1 & 205 & 2,777 \\
\hline & Pengawasan & 1,981 & 674 & 8,635 & 1 & ,003 & 7,250 \\
\hline & Sarpras & 4,240 & 1,552 & 7,465 & 1 &, 006 & 69,411 \\
\hline & Constant & $-15,199$ & 4,847 & 9,834 & 1 &, 002 &, 000 \\
\hline
\end{tabular}

The results of the analysis of binary logistic regression parameters are presented in table IV.14 above. This analysis serves to see the effect partially or individually of each independent variable. The results of the analysis provide information that for the knowledge variable has a sig value of 0.010 . This value is smaller than 0.05 so that it can be concluded that there is a significant influence individually on the variable knowledge of compliance in applying the Precaution Standard. The trust variable has a sig value of 0.721 . This value is greater than 0.05 so the conclusions obtained based on the results of the analysis are that there is no individual significant influence on the variable trust in the application of the Precaution Standard.

The sig value for the motivation variable is 0.205 . This value is greater than 0.05 so the conclusion that can be taken is that the motivation variable does not have a significant influence individually on compliance in the application of the Precaution Standard.

The sig value for infrastructure facilities is 0.006 . This value is smaller than 0.05 so that the conclusion obtained is that there is a significant influence individually on the availability of infrastructure tools for compliance with the application of the Precaution Standard.

The sig value between the supervision variable and compliance is 0.003 . This value is smaller than 0.05 so the conclusion obtained is that there is a significant influence between the supervision carried out on the application of the Precaution Standard.

The results of the above analysis provide a conclusion that there are 3 variables that have a significant influence individually, namely knowledge, supervision, and availability of infrastructure with supervision variables are variables that have the most individual influence compared to other variables.

\section{DISCUSSION}

1. Factors Affecting the Dentist's compliance in the Implementation of the Precaution Standard at RSGM IIK BW Kediri.

\section{a. Knowledge Factor}

The results of the statistical analysis showed that there was a significant influence on the knowledge of compliance with the application of the precaution standard at the Dental and Mouth Hospital $(\mathrm{p}=0.010)$. This might be due to the new knowledge about the precaution standard, which according to Soekamto (1997) changes new behavior in a person is a complex process and requires a relatively long time. This is also in line with Haridi's research, et al. (2016), who said that there needs to be a systematic training program to support knowledge so that the implementation of the precaution standard can be implemented well. The results showed that only $62.7 \%$ of respondents were dentists at RSGM IIK BW Kediri who had good knowledge of the Precaution Standards. This is in accordance with the research conducted by Hassan Kasim Haridi1, Abdalmohsen Saud Al-Ammar and Moazzy Ibraheim Al-Mansour (2016) where there were 38.4\% good knowledge of the standard precaution carried out in dental and oral hospitals, where 51,5\% of knowledge in the good category is obtained by the dentist. This condition may occur due to the lack of socialization of the hospital regarding the 
precaution standard, especially for the dentist co-ordinates who are new to patients in their first year. In addition, it may be due to factors that are still relatively young and lack experience and understanding and training in standard precautions in hospitals.

From the data obtained, as many as $22 \%$ of respondents consider the evaluation of patients to be less important to be done again to prevent cross infection. As many as $23 \%$ of respondents did not know that disposable equipment and medical waste disposal, especially in relation to the use of masks and gloves for each patient, from reviews on the ground, many respondents found only using masks and gloves only for all patients. This reluctance to replace is due to the lack of knowledge about the possibility of infection due to the use of equipment. In terms of hand washing the respondent also received a less positive response, many of the respondents who did handwashing before and after using gloves, washed their hands before and after taking action despite wearing gloves and other personal protective equipment. This action is important to reduce the microorganism that is in the hand so that the spread of infection can be reduced and the work environment is protected from infection (Kurniawati \& Nursalam, 2007).

\section{Factors of Availability of Infrastructure}

The results of the statistical analysis show that there is an influence of the availability of infrastructure facilities on the application of precaution standards in hospitals $(p=0.006)$. The results of this study are in line with Yuliana (2012) in RSKO Jakarta towards standard vigilance resulting in the influence of the availability of standard precautions on doctor. it was concluded that there was a relationship between the availability of facilities and the application of standard precautions to nurses and the availability or availability of facilities would cause the application of precaution standards to be high and low in carrying out their duties and responsibilities.

The availability of facilities, especially PPE, is a very important supporting factor for dentist compliance in implementing the precaution standard, especially in serving patients in hospitals, accidentally or intentionally contaminated hospital equipment, where dangerous equipment contamination is caused by the HIV / AIDS virus (Nurkhasanah, 2013).

From the results of the study, it was found that respondents who stated the availability of infrastructure facilities in hospitals were stated to be complete, namely as many as $79.1 \%$ of respondents. The availability of facilities for washing hands with antisepic fluids, the availability of PPE that is used during inspection and action, the availability of trash bins that have been separated between medical and non-medical waste. However, there are several facilities that are owned but not carried out optimally in the implementation of the precaution standard, for example the availability of facilities in the form of single-use equipment which is rarely observed is sometimes the source of cross infection. Among the koas there are still many who are reluctant to replace the gloves that are used after taking action on one patient and moving to another patient. The use of masks is also felt to be inadequate where masks are used only one to one working day in handling patient patients.

Some students cleaned the equipment contaminated with running water and soap and then took it to the sterilization room, but did not pay attention to self-protection when cleaning the tool. Students should clean the washing equipment by using $0.5 \%$ chlorine solution and sterilize the equipment before reuse. The unavailability of self-protection equipment when cleaning equipment and the lack of student awareness resulted in prevention of infection when handling instruments was ignored by most of the clinical clerical students of the Dental and Oral Hospital IIK Bhakti Wiyata Kediri. for the sterilisasia process the recommended tool to prevent bacterial and viral growth in the dental practice tool at RSGM also has not provided a sterilizer in the RSGM environment. With the availability of complete facilities, it is expected that Koas Dentists can be motivated to apply universal precaution. 


\section{CONCLUSION}

Based on the results of research and discussion, it can be concluded as follows:

1. The dentist's knowledge of good standard precaution is $62.7 \%$, enough $31.3 \%$ and less category $6.0 \%$.

2. Dentist's trust in infectious diseases Very good $40.3 \%$ in terms of high risk of the possibility of contracting hepatitis B, AIDS and tuberculosis, and good (56.7\%) and less (3.0\%)

3. Supervision or supervision by supervising doctors is considered good with $49.3 \%$

4. Motivation on dentist counsels is considered good with a percentage of $52.2 \%$

5. Availability of infrastructure facilities in rsgm is assessed complete with a percentage of $79.1 \%$

6. Respondents' compliance in implementing standard precaution as much as $67.2 \%$ or as many as 45 counsels in the obedient category and 22 people or $32.8 \%$ in the category did not comply with the application of the precaution standard.

7. There is a significant influence simultaneously or together with the variables of knowledge, trust, supervision, motivation, availability of sarpras on compliance in the application of Standard Precaution

8. Monitoring variables are variables that have the most individual influence compared to other variables.

9. That there are 3 variables that have a significant influence individually, namely knowledge, supervision, and availability of infrastructure

\section{SUGGESTION}

\section{For Research Sites}

To improve quality services for RSGM IIK Kediri patients and prevention of cross infection, special attention needs to be paid to such things as:

a. Providing infrastructure facilities such as wet sterilizers in the form of autoclaves to ensure the sterility of the equipment to be used

b. Provides hansscoon and disposable masks for one patient

c. Providesberber dam, jaspractics, patient chest pads.

d. Monitor and monitor the implementation of precaution standards for practicing students

2. For Practice Students

a. The knowledge of dentists about the application of precaution standards needs to be improved through involving dentists in training the standard precaution standard so that the knowledge of dentists is in accordance with the application of the precaution standard.

b. $\quad$ Students master the SOP before and after the action to patients at RSGM IIK Kediri.

c. Improving the cleanliness of the work environment, as well as the sterility of Personal Protective Equipment and Equipment before and after student use for action to patients at RSGM IIK Kediri

\section{For Patients}

a. Increase patient knowledge about infection prevention and control at RSGM IIK Kediri

b. Improve infection prevention measures by washing hands before entering the treatment room at RSGM IIK Kediri

\section{For Further Researchers}

For the next researcher to do a similar study related to the application of standard precautions by dentists by examining variables that might be related or related to the behavior of dentists to comply with applying standard precautions when performing services to patients 


\section{REFERENCES}

Arikunto, S. (2010). Research procedures: A Practice Approach. Jakarta. Rineka Cipta.

Azwar, S. (2009). Human Attitudes Theory and Measurement. Yogyakarta: Liberty.

Budiharto. (2015). Introduction to health behavior science and dental health education. Jakarta: EGC.

Cuming, \& Richard. (2009). Factors Surgical Team Members Perceive Influence Choices of Wearing or Not Wearing Personal Protective Equipment During Operative / Invasive Procedures. Miami: Florida International University Dissertation.

Dawson, M. et al. (2012). Effective Clinical Supervision for Regional Allied Health Professionals The Supervisee's Perspective. Australian Health Review, 36 (1) 92-97.

Dervish, \& Hikmawati, M. (2017). Public Health in prospective socioantropology. Makassar: Sah Media CV.

Dinata, A. (2016). Eradication of Animal Source of Disease. Accessed 15 June 2018http: //www.litbang.depkes.go.id/lokaciamis/artikel/nyamuk-arda.html.

Fatekurohman, M. (2013). Estimation of the function of survival of hepatitis virus in Kab. Jember. Jurnal ilmu dasar;: 8(2): 135-41.

Feng, X., Q. et al. (2011). The Relationship Between Management Safety Commitment and Patient Safety Culture. International Nursing Review, 58(2), 249-254.

Haridi, Kasim, H., Al-Ammar, Saud, A., \& Ibraheim, A., M. (2016). Knowledge of Dental Health Care Workers' about Standard Precautions Guidelines at Health Care Facilities in Hail Region, Saudi Arabia. International Journal of Advanced Research (2016), Volume 4, Issue 1, 1375- 1385. 